\title{
SMST 2019 Conference Being Held in Konstanz, Germany, in May 2019
}

The International Conference on Shape Memory and Superelastic Technologies (SMST) will be held May 13-17, 2019 at The Bodenseeforum in Konstanz, Germany. Dr. Ulrich Muerrle will serve as conference chair for the event, with Dr. Matthias Mertmann serving as co-chair. Additional members of the Organizing Committee include Dr. Tom Duerig, Dr. Darel Hodgson, FASM, Dr. Alan Pelton, FASM, and Mr. Jeremy Schaffer.

SMST is the leading worldwide conference and exposition for the shape memory and superelastic technologies and is highly focused on the manufacturing and application of shape memory materials. The preeminent experts in all aspects of working with Nitinol will be present at this conference.

Monday will feature a Nitinol workshop, along with the Welcome Reception. The Exhibitor and Poster Reception will take place on Tuesday. There will be an exciting networking opportunity on Wednesday, on a dinner cruise on Lake Constance aboard the MS Graf Zeppelin. The CASMART 3rd Design Challenge will take place on Thursday. Technical sessions will be held during the week, Tuesday through Friday.

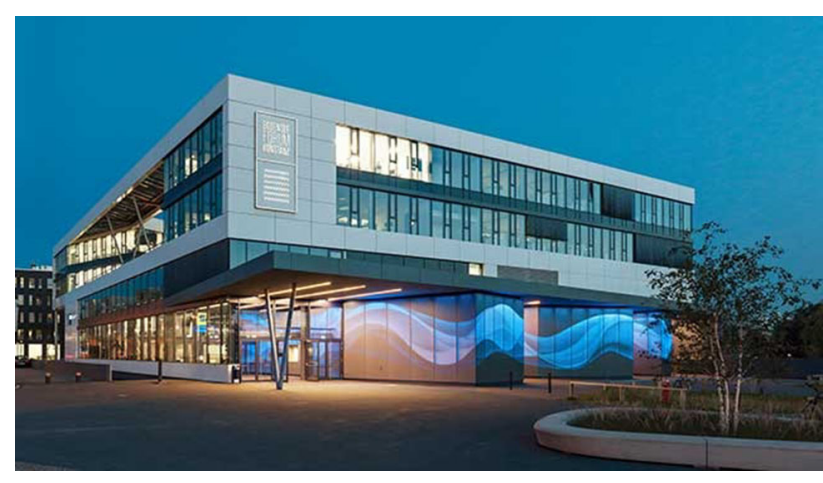

The Bodenseeforum Konstanz

Konstanz is the largest city on Lake Constance, with a harbor promenade at the Constance Bay, and a historic city center. The area is also home to the University of Excellence Constance and the Hochschule Konstanz University of Applied Sciences (HTWG).

For more information and to register for SMST 2019, please visit: https://www.asminternational.org/web/smst2019. 